\title{
COVID-19 PANDEMIC: PSYCHO-SOCIAL CONSEQUENCES DURING THE SOCIAL DISTANCING PERIOD AMONG NAJRAN CITY POPULATION
}

\author{
Awad Mohammed Al-Qahtani ${ }^{1}$, Wafaa Taha Elgzar ${ }^{2}$ \& Heba Abdel-Fatah Ibrahim ${ }^{2}$ \\ ${ }^{I}$ Family Medicine Department, College of Medicine, Najran University, Najran, Saudi Arabia \\ ${ }^{2}$ Maternity and Childhood Nursing Department, Nursing College, Najran University, Najran, Saudi Arabia
}

received: 12.5.2020;

revised: 22.5.2020;

accepted: 29.5.2020

\section{SUMMARY}

Background: COVID-19 is a global pandemic that endanger the health and enforced social distancing for the whole world. Social distancing may generate stress, anxiety, and depression. Understanding the psychosocial consequences of COVID19 during social distancing may help decision-makers to take suitable decisions that help in increasing awareness.This study aims to evaluate the psychosocial consequences of COVID-19 pandemic during the social distancing period and explore the relationship between social media use and psychological stress during COVID-19 outbreak among Najran city population.

Subjects and methods: Descriptive correlational research design was utilized to carry out this study. A snowball sampling technique, was used to recruit participants live in Najran city during the COVID-19 pandemic (1508 participant).

Results: A statistically significant differences $(P<0.05)$ are observed between Saudi and non-Saudi participants in all social aspects assessed except for time spent on social media. In addition, a high mean of depression, stress, and anxiety subscale scores are observed in non-Saudi compared to the Saudi participants with statistically significant differences ( $p=0.000)$. As well as high DASS-21 total scores in non-Saudi compared to the Saudi participants. Also, there are positive statistically significant correlations $(\leq 0.05)$ between participants' time spent in social media and their depression, stress, anxiety, and total DASS scores during the COVID-19 outbreak.

Conclusion: The findings of the present study indicate that COVID-19 pandemic generates stress, anxiety and depression among Najran population especially, non-Saudi. This poor psychological condition is exaggerated with prolonged social media use. COVID-19 also has negative impact on social wellbeing and use of social media cannot replace direct contact with friends. The current study results may be utilized to formulate interventions that enhance psychosocial health and resilience during the COVID-19 outbreak.

Key words: anxiety - COVID-19 - depression - mental health - stress - social distancing

$* * * * *$

\section{INTRODUCTION}

At the end of 2019, several consecutive cases of severe pneumonia have been recorded in Wuhan, China. At the beginning of 2020 WHO confirmed the COVID19 outbreak (Lucey \& Sparrow 2020) WHO 110 situation reports on 9 May 2020 showed a sharp elevation in the number of cases internationally to 3855812 confirmed cases with death 265862 with death rate $6.89 \%$. The covid-19 spread all over the world with many cases as in the western Pacific (158 523), Europe (1 682 338), Southeast Asia (90 808), Eastern Mediterranean (224 022), America (1 636 841) and Africa (40 568). The WHO risk assessment is very high. COVID-19 spread very rapidly, which makes the entire world in a panic attack. For Saudi Arabia, the number of confirmed cases jumped to 37136 cases with 239 deaths. The death rate is $0.64 \%$, which makes the government take numerous protective and preventive actions. The most affected KSA regions are Riyadh, Jeddah, Mecca, Elmadina, Elkobar, Dammam, and Tabuk (WHO 2020a).

Clinical picture found in COVID-19 vary widely. It includes, but not limited to, high fever in most of cases, dry cough, generalized malaise and body ache, short- ness of breath, dyspnoea and respiratory distress in some cases. Another reported symptom includes haemoptysis and gastrointestinal disturbances. Some laboratory finding showed leucopenia and lymphopenia. Researches also shows vital signs stability in most cases. The pathophysiological consequences of COVID-19 is still unclear but septic shock, acute kidney injury, virusinduced cardiac injury, severe pneumonia and severe respiratory distress (Hui et al. 2020, WHO 2020b).

COVID-19 infection is not linked to specific country, ethnicity, or religion; it is a worldwide pandemic that mainly affects low immunity people. COVID-19 patient cannot be palmed for catching the infection. The society should provide support, empathy, and compassion for these people (WHO 2020c).

WHO had issued a management guide to deal with COVID-19 mainly build on preventive measures and strict infection control precautions, including isolation. It incorporates precautions applied at triage, droplet precautions, contact precautions, and airborne precautions when performing aerosol-generating procedures (WHO 2020b). These infection control precautions need knowledge and experiences to be applied. It also requires high self-efficacy and low perceived barriers for care. 
KSA government takes a serious actions to decrease COVID-19 infection. It include online learning in schools and universities, decrease crowdedness in public places, strict infection control precautions in hospitals, stop airlines flights, Delaying Hajj and Umrah, curfew and social distancing.

Many studies concluded numerous psychosocial consequences of social distancing applied in different pandemics. These consequences include, but not limited to, anxiety, frustration, feels threatened, confusion, financial harm, and post-traumatic stress. Other studies reported a sense of loneliness, information deficiency, anger, sense of loss, and stigma (Inter-agency standing committee 2020).

During social distancing, social media is a doubleedged sword. In one way, it's a good source of information and allows an effective way of communication. Furthermore, it may help to spend time in a funny conversation during quarantine. On the other hand, it may contain wrong information that may exaggerate fear and stress. In addition, it may encourage people to practice harmful behaviours and decreased perceived health status (Ahmad et al. 2020, Anderson et al. 2020).

Several researches are concerned with the psychosocial consequences of the pandemic. They reported that it has numerous consequences in both adults and children. These consequences include infection, fear for self, and loved people. In addition, people with chronic illnesses have special fears, worries, and deteriorating health conditions because they are at higher risk for acquiring infection. Other problems, including lifestyle disturbances, sleeping pattern disturbances, drug addiction, and financial problems (Fisher \& Heymann 2020, WHO 2020d) The financial problem may result from limited people ability to work. Some poor people may have severe socio-economic stress, which may be longlasting. This necessitates community and governmental support for those population (Jeong et al. 2016).

COVID-19 begins only since five months. Therefore, there are extremely few studies investigated its psycho-social consequences. So, the current study aims to evaluate the psycho-social consequences of COVID19 pandemic during the social distancing period among Najran city population and exploring the relationship between social media use and psychological stress during COVID-19 outbreak.

\section{SUBJECT AND METHODS}

This is descriptive correlational study that was conducted at Najran city. A snowball sampling technique, amid to recruit participants live in Najran city during the COVID-19 pandemic, was utilized. Online survey was first disseminated to university students and academic/ administrative staff; later, they disseminated it to their relatives, friends, and others.

Sample size was statistically calculated using Epiinfo program where; sample size for frequency in a population size is 331683 according to the last population survey of general authority for statistics, KSA. Confidence level $99.99 \%$, expected frequency $50 \%$, design effect $1 \%$. The sample size is 1508 . The Inclusion criteria include; social media users, aged more than 19 years old, give consent for participation.

Three tools were used for data collection. Tool I; self-administrated questionnaire. It was constructed by the researchers after revising related literature. It involved two main parts; Part one it was designed to collect basic data such as gender, age, educational level, residence, nationality, marital status, occupation, income, parental status. Part two; the social consequences of social distancing during the time of COVID 19 pandemic. It includes social relationship alternatives, the effect of social distancing on family relation, time and types of social media use. Tool II; Depression, Anxiety, and Stress Scale (DASS-21). The psychological consequences during the social distancing period was assessed using the DASS-21. This scale comprises three subscales and contains 21 questions. The questions of the scale are equally divided to assess depression, anxiety, and stress. The total of each subscale scoring ranged from 0 to 21 (Lovibond \& Lovibond 1995).

The instruments were tested for face, content, and construct validity by a jury of 5 expertise in the nursing and medical field. Instrument reliability was done using Cronbach's Alpha coefficient test. It indicated high reliability $(\mathrm{r}=0.905)$.

After approval of the research proposal by the deanship of scientific research at Najran University, informed consent was associated with the online survey The participant anonymity was be applied.

Data collection was done from the beginning of March until the end of April 2020 through online survey. The online survey was disseminated through social media, including WhatsApp, Snapchat, and twitter groups. Joined with the questionnaire link explanation of the study purpose was done. The confidentiality of the data was assured.

\section{Data analysis}

After the completion of data collection, SPSS version 23 was used to analyze data. Descriptive statistics as number, percentage, mean $\pm \mathrm{SD}$ were used to describe the data. Differences between groups and correlations between variables were investigated.

\section{RESULTS}

Table 1 illustrates that $70 \%$ of the study participants are females, and $83 \%$ of them are University educated. Around two- thirds $(65.2 \%)$ of them are married, and $70.6 \%$ of them are Saudi citizens. One-third of the study participants work on governmental organizations, while $26.7 \%$ don't work. In addition, $34.3 \%$ of the study participants have a monthly income of less than 5000 SAR. Lastly, $65.1 \%$ of them have children. 
Table 1. Basic data of the study participants $(n=1508)$

\begin{tabular}{|c|c|c|}
\hline Basic data & No (1508) & $\%$ \\
\hline \multicolumn{3}{|l|}{ Sex } \\
\hline Male & 453 & 30 \\
\hline Female & 1055 & 70 \\
\hline \multicolumn{3}{|l|}{ Education } \\
\hline Read and write & 31 & 2.1 \\
\hline Secondary school & 224 & 14.9 \\
\hline University & 1253 & 83 \\
\hline \multicolumn{3}{|l|}{ Marital status } \\
\hline Married & 983 & 65.2 \\
\hline Single & 473 & 31.4 \\
\hline Widow & 15 & 1 \\
\hline Divorced & 37 & 2.4 \\
\hline \multicolumn{3}{|l|}{ Nationality } \\
\hline Saudi & 1065 & 70.6 \\
\hline Non-Saudi & 443 & 29.4 \\
\hline \multicolumn{3}{|l|}{ Working condition } \\
\hline Governmental work & 551 & 36.5 \\
\hline Private work & 237 & 15.7 \\
\hline Student & 317 & 21.1 \\
\hline Don’t work & 403 & 26.7 \\
\hline \multicolumn{3}{|l|}{ Monthly income } \\
\hline$<5000 \mathrm{SAR}$ & 518 & 34.3 \\
\hline 5000-10,000SAR & 493 & 32.7 \\
\hline$>10,000 \mathrm{SAR}$ & 497 & 33 \\
\hline \multicolumn{3}{|l|}{ Parenting } \\
\hline Yes & 981 & 65.1 \\
\hline No & 527 & 34.9 \\
\hline Age $($ Mean \pm SD $)$ & $34.324 \pm 10.423$ & \\
\hline
\end{tabular}

Table 2 shows a statistically significant differences $(\mathrm{P}<0.05)$ between Saudi and non-Saudi participants in all social aspects assessed except for time spent on social media use. Both groups used social media nearly equally in a mean $4.6089 \pm 3.141$ hours for Saudi and $4.7381 \pm 3.266$ for Non-Saudi. Twitter $(61.13 \%)$ is the most used social media among Saudi participants compared to Facebook (53.5\%) among non-Saudi. Furthermore, $51.44 \%$ of the Saudi population agree that social distancing does not affect social relations compared to $45.82 \%$ of the non-Saudi. Also, $43.57 \%$ of Saudi participants reported that social media use does not give the same results as direct contact with friends compared to $58.92 \%$ of the non-Saudi. Around two-thirds (65.45\% and $64.04 \%$ ) of Saudi participants see that social distancing gives a chance for comfort/mind pace as well as participation in household activities and cooperation between couples compared to $49.44 \% 49.66 \%$ to the non-Saudi population, respectively. In addition, social distancing gives a chance to consolidate family relations in the opinion of $66.2 \%$ of Saudi participants compared to $64.79 \%$ among non-Saudi.

Table 3 indicates high mean depression, stress, and anxiety subscale scores are observed in non-Saudi compared to the Saudi participants with statistically significant differences $(\mathrm{p}=0.000)$. As well as high DASS21 total scores are observed in non-Saudi compared to the Saudi participants with the mean score $16.31 \pm 13.93$ and $23.25 \pm 15.76$ for Saudi and non-Saudi participants respectively, with statistically significant difference $(\mathrm{t}=7.251, \mathrm{p}=0.000)$.

Table 2. Social consequences of social distancing during COVID-19 pandemic among Saudi and non-Saudi participants $(\mathrm{n}=1508)$

\begin{tabular}{|c|c|c|c|c|c|c|c|c|}
\hline \multirow[b]{2}{*}{ Social consequences } & \multicolumn{3}{|c|}{ Saudi No $(1065)$} & \multicolumn{3}{|c|}{ Non Saudi No (443) } & \multirow{2}{*}{$\begin{array}{l}\text { Signifi- } \\
\text { cance } \\
\text { test }\end{array}$} & \multirow[b]{2}{*}{$P$ value } \\
\hline & $\begin{array}{l}\text { Yes } \\
\mathrm{n}(\%)\end{array}$ & $\begin{array}{c}\text { To some } \\
\text { extent } \mathrm{n}(\%)\end{array}$ & $\begin{array}{l}\text { No } \\
\mathrm{n}(\%)\end{array}$ & $\begin{array}{l}\text { Yes } \\
\mathrm{n}(\%)\end{array}$ & $\begin{array}{c}\text { To some } \\
\text { extent } \mathrm{n}(\%)\end{array}$ & $\begin{array}{l}\text { No } \\
\mathrm{n}(\%)\end{array}$ & & \\
\hline $\begin{array}{l}\text { Social distancing negatively } \\
\text { affected social relation }\end{array}$ & $\begin{array}{c}170 \\
(15.96)\end{array}$ & $\begin{array}{c}347 \\
(32.58)\end{array}$ & $\begin{array}{c}548 \\
(51.46)\end{array}$ & $\begin{array}{c}128 \\
(28.89)\end{array}$ & $\begin{array}{c}112 \\
(25.28)\end{array}$ & $\begin{array}{c}203 \\
(45.82)\end{array}$ & $\begin{array}{c}\mathrm{FET}= \\
32.328\end{array}$ & $0.000^{*}$ \\
\hline $\begin{array}{l}\text { Social media use gives the same } \\
\text { results as direct contact with friends }\end{array}$ & $\begin{array}{c}207 \\
(19.44)\end{array}$ & $\begin{array}{c}394 \\
(37.00)\end{array}$ & $\begin{array}{c}464 \\
(43.57)\end{array}$ & $\begin{array}{c}44 \\
(9.93)\end{array}$ & $\begin{array}{c}138 \\
(31.15)\end{array}$ & $\begin{array}{c}261 \\
(58.92)\end{array}$ & $\begin{array}{l}\mathrm{FET}= \\
36.228\end{array}$ & $0.000^{*}$ \\
\hline $\begin{array}{l}\text { Social distancing gives chance } \\
\text { for comfort and mind pace }\end{array}$ & $\begin{array}{c}697 \\
(65.45)\end{array}$ & $\begin{array}{c}308 \\
(28.92)\end{array}$ & $\begin{array}{c}60 \\
(5.63)\end{array}$ & $\begin{array}{c}219 \\
(49.44)\end{array}$ & $\begin{array}{c}174 \\
(39.28)\end{array}$ & $\begin{array}{c}50 \\
(11.29)\end{array}$ & $\begin{array}{l}\mathrm{FET}= \\
36.651\end{array}$ & $0.000 *$ \\
\hline $\begin{array}{l}\text { Social distancing gives chance } \\
\text { to practice household activities } \\
\text { and cooperation between couples }\end{array}$ & $\begin{array}{c}682 \\
(64.04)\end{array}$ & $\begin{array}{c}296 \\
(27.79)\end{array}$ & $\begin{array}{c}87 \\
(8.17)\end{array}$ & $\begin{array}{c}220 \\
(49.66)\end{array}$ & $\begin{array}{c}147 \\
(33.18)\end{array}$ & $\begin{array}{c}76 \\
(17.16)\end{array}$ & $\begin{array}{l}\mathrm{FET}= \\
35.859\end{array}$ & $0.000^{*}$ \\
\hline $\begin{array}{l}\text { Social distancing gives chance } \\
\text { to consolidate family relations }\end{array}$ & $\begin{array}{c}705 \\
(66.20) \\
\end{array}$ & $\begin{array}{c}273 \\
(25.63) \\
\end{array}$ & $\begin{array}{c}87 \\
(8.17) \\
\end{array}$ & $\begin{array}{c}287 \\
(64.79) \\
\end{array}$ & $\begin{array}{c}98 \\
(22.12) \\
\end{array}$ & $\begin{array}{c}58 \\
(13.09) \\
\end{array}$ & $\begin{array}{l}\text { FET }= \\
9.216 \\
\end{array}$ & $0.010^{*}$ \\
\hline $\begin{array}{l}\text { The most used social media } \\
\text { at COVID-19 social distancing }\end{array}$ & $\begin{array}{c}\text { No } \\
(1065)\end{array}$ & $\%$ & & $\begin{array}{c}\text { No } \\
(443)\end{array}$ & $\%$ & & & \\
\hline Facebook & 2 & 0.19 & & 237 & 53.50 & & & \\
\hline Twitter & 651 & 61.13 & & 176 & 39.73 & & $\begin{array}{c}\mathrm{FET}= \\
724.165\end{array}$ & $0.000^{*}$ \\
\hline Telegram & 17 & 1.60 & & 0 & 0.00 & & & \\
\hline WhatsApp & 316 & 29.67 & & 20 & 4.51 & & & \\
\hline Instagram & 79 & 7.42 & & 10 & 2.26 & & & \\
\hline $\begin{array}{l}\text { Time spent on social media use } \\
(\text { Mean } \pm \text { SD) }\end{array}$ & & $4.6089 \pm 3.141$ & & & $4.7381 \pm 3.266$ & & $\mathrm{t}=0.719$ & 0.472 \\
\hline
\end{tabular}

FET - Fisher exact test; $\mathrm{t}$ - Independent t-test; $*$ P significant at $\leq 0.05$ 
Table 3. Psychological consequences of social distancing during COVID-19 pandemic among Saudi and non-Saudi participants $(\mathrm{n}=1508)$

\begin{tabular}{lcccc}
\hline \multicolumn{1}{c}{ DASS-21 } & $\begin{array}{c}\text { Saudi } \\
\text { Mean } \pm \text { SD }\end{array}$ & $\begin{array}{c}\text { Non-Saudi } \\
\text { Mean } \pm \text { SD }\end{array}$ & t test & P value \\
\hline Depression score & $4.77 \pm 5.20$ & $7.81 \pm 5.47$ & 6.809 & $0.000^{*}$ \\
Anxiety score & $5.95 \pm 5.46$ & $7.23 \pm 5.49$ & 4.724 & $0.000^{*}$ \\
Stress score & $5.59 \pm 5.29$ & $8.21 \pm 5.82$ & 8.498 & $0.000^{*}$ \\
Total DASS score & $16.31 \pm 13.93$ & $23.25 \pm 15.76$ & 7.251 & $0.000^{*}$ \\
\hline
\end{tabular}

$\mathrm{t}$ - Independent $\mathrm{t}$-test; $* \mathrm{P}$ significant at $\leq 0.05$

Table 4. Correlation coefficient between participant' time spend in social media and their psychological consequences during COVID-19 pandemic $(n=1508)$

\begin{tabular}{lcc}
\hline \multicolumn{1}{c}{ DASS-21 } & \multicolumn{2}{c}{ Time spend in social media } \\
& $\mathrm{r}$ & P value \\
\hline Depression score & 0.335 & $0.000^{*}$ \\
Anxiety score & 0.258 & $0.000^{*}$ \\
Stress score & 0.248 & $0.000^{*}$ \\
Total DASS score & 0.301 & $0.000^{*}$ \\
\hline
\end{tabular}

$\mathrm{r}$ - Pearson correlation coefficient; $* \mathrm{P}$ significant at $\leq 0.05$

Table 4 demonstrates that there are positive statistically significant correlations $(\leq 0.05)$ between participants' time spent in social media and their depression, stress, anxiety, and total DASS scores during the COVID-19 pandemic.

\section{DISCUSSION}

While all the world was waiting for 2020 to celebrate a new and unique year, the corona virus's family has a different opinion. They developed a new fetal infection that told all the world that it would not be the year of celebration; it will be the year of fear, stress, depression, loss of loved people, and social distancing. COVID-19, name linked to numerous psychosocial consequences that affected all peoples at all levels, ethnicity, and countries. While people plan to take numerous technological advances in 2020, COVID-19 comes to teach them how to wash their hands, keep cleanliness and social distances.

The current study results show statistically significant differences $(\mathrm{P}<0.05)$ between Saudi and non-Saudi participants in all social aspects assessed except for time spent on social media use. Both groups used social media nearly equally in a mean of $4.6089 \pm 3.141$ hours for Saudi and 4.7381 \pm 3.266 for Non-Saudi. It is expected that non-Saudi participants will be more affected by social distancing because they are away from their homes, families, and countries. Therefore, they will be more distressed when imposed to stay at home. Furthermore, most of them may be economically affected, which imposed more stress on them. Being socially away from families is stress on itself and exaggerated by being trapped in another country - also, the condition of uncertainty surrounding the pandemic as what will happen and when it will end.
No available studies reached on a database that compares the psychosocial consequences between expatriate and non- expatriate populations at the time of COVID-19 pandemic. In line with the present study is the report provided by Haleem et al. 2020. They reported that COVID-19 negatively affects all aspects of daily life activities. They illustrated that as the severity of pandemic increased all the countries enforced strict social distancing percussions over their population. They added that social distancing induced undue stress among the community due to restrictions on everything they usually do. Such as closer of prayer places and restricting celebrations, stopping air lines, and Isolation during religious events.

Furthermore, Debanjan and Rai 2020 investigated COVID-19 social distancing and its impact on a sense of loneliness. They reported that the people replaced the direct social contact with the online communication. They further added that online communication could not prevent the sense of social loneliness as the modern man in the time of technology, social media, airlines, and other methods of communication did not learn to spend time with himself. In addition, he will be punished if he breaks social distance. People are forced to meet loved ones only through the virtual world. They also emphasized that people need even minor interaction with neighbors or even stranger to share their fear. It is the time for humanity to share unity and face the threat together from the concept " we are all in this together". The current study illustrated that Twitter is the most used social media among Saudi participants compared to Facebook among non-Saudi. Ahmad et al. 2020 investigated the relation between social media use and COVID-19 panic among Iraqi population and reported that $82.6 \%$ among his participants in Iraqi used Facebook as social media at time of COVID-19 pandemic. The young male used Facebook more than females. The type of social media used is unique to each nationality and differ also according to age.

In the current study, around half of the Saudi population agree that social distancing does not affect social relations compared to $45.82 \%$ of the non-Saudi. This result may be attributed that most of Saudi families are extended one that mostly lives in the same large house or more than a home but the same cluster near to each other. So, they can meet each other's even 
at the time of social distancing. On the other hand, the non-Saudi population lives away from each other and meets at the weekend in a public garden to communicate with friends, who mostly substitute their families. Therefore, $43.57 \%$ of Saudi participants reported that social media use does not give the same results as direct contact with friends compared to $58.92 \%$ of the non-Saudi. In addition, around twothirds of Saudi participants see that social distancing gives a chance for comfort/mind pace as well as participation in household activities and cooperation between couples compared to one half of the nonSaudi population. Besides, social distancing gives a chance to consolidate family relations in the opinion of both Saudi and non-Saudi participants. Again, no available evidence found on the international database that discussed the social consequences of COVID-19 from this point of view. Therefore, this is the first study that compared the psychosocial consequences between expatriate and non- expatriate populations at the time of the COVID-19 pandemic.

In the present study, high mean depression, stress, and anxiety subscale scores are observed in non-Saudi compared to the Saudi participants with statistically significant differences, whereas the average scores are mild in Saudis and moderate in non-Saudis participants in the three subscales and total DAAS. These results appear to be reasonable, while the reason for the increase in depression, stress and anxiety, and the total DASS scores for non-Saudis may be attributed to increased anxiety and stress towards the family in the motherland and the severe fear of the unknown fate in a country other than his own due to the sharp increase in cases of COVID-19 in both countries. In addition to the WHO reports on the extent, severity, and potential deaths of the disease in most parts of the world.

There are many recent Chinese studies on COVID19 were indicated similar results. The first Wang et al. (2020a) who had evaluated the stress, anxiety, and depression of the Chinese population during the COVID19 pandemic. They found moderate stress, anxiety, and depression, while the mean scores were 7.76, 6.16, and 6.25 , respectively. The second, Wang et al. (2020b) who had studied psychological impact and associated factors during the COVID-19 pandemic among Chinese population. They reported that more than half of their study participants ranked their psychological consequences as moderate to severe. The third, Li et al. (2020) who had explored the impact of COVID-19 on population psychological health. Their results showed the appearance of negative feelings (anxiety and depression) was observed among Active Weibo users after the announcement of the COVID-19 outbreak.

Moreover, in this regard, a recent study in Iran conducted by Zandifar and Badrfam (2020) to evaluate the impact of the COVID-19 outbreak on mental health. The authors emphasized the role of unpredictability, the significance of the infection, misinformation, and social distancing in contributing to anxiety, stress, and depression. They also stressed the need for both psychological health services, mainly for vulnerable people, and the establishment of social capital to decrease the adversarial psychological consequences of COVID-19. In addition, another study conducted in Japan by Shigemura et al. 2020 emphasized the economic effect of COVID-19 and its impacts on mental well-being. They stated that the increased levels of fears and anxiety due to resources hoarding and storage among the Japanese population. The study also recognized people at risk of adverse psychological health consequences, including patients and their families with COVID-19, persons with chronic or mental illness, and health team.

Furthermore, the results of the current study are consistent to previous studies, which showed that public health emergencies (such as SARS) triggered a series of emotional stress response containing a higher level of anxiety, stress and less positive emotions (Maunder et al. 2003, Tam et al. 2004). COVID-19 affected various frontiers of life and initiated many individual and group psychosocial problems such as panic, anxiety, depression, post-traumatic stress disorders, suspicion, discomfort, and racism, etc. (Jakovljevic et al. 2020).

The current study also indicated a positive significant correlation between participants' time spent in social media and their depression, stress, anxiety, and total DASS scores during the COVID-19 pandemic. Many studies indicated that increased time spent on social media and increased frequency significantly associated with stress, anxiety, and depression (Shensa et al. 2018, Vannucci et al. 2017, Becker et al. 2013). In addition, it may lead to negative online experiences, less personal social interactions, and a lower ability to maintain attention (Baek et al. 2013) Moreover, Ahmad et al. 2020 had concluded that social media use is sharply increased during COVID-19 pandemic. He further added that the increased frequency of social media use is related to increased panic and stress among their participants.

\section{CONCLUSION AND IMPLICATION}

The findings of our study indicate high mean depression, stress, and anxiety scores in non-Saudi compared to the Saudi participants. Also, a significant differences are observed between Saudi and non-Saudi participants in all social aspects assessed except for time spent on social media use. Increased time spent on social media significantly associated with more significant psychological consequences as increased level of stress, anxiety and depression. The current study results can be utilized to formulate interventions that enhance psychosocial health and resilience during the COVID-19 pandemic. 


\section{Acknowledgements:}

The authors would like to express their gratitude to the ministry of education and the deanship of scientific research - Najran University - Kingdom of Saudi Arabia for their financial and technical support under code number (NU/MID/18/010)

Conflict of interest: None to declare.

\section{Contribution of individual authors:}

Awad Mohammed Al-Qahtani: idea, concept and design of the article, first manuscript draft, manuscript revisions, approval of the final version.

Wafaa Taha Elgzar: concept and design of the article, data collection, literature review, interpretation of data, first manuscript draft, approval of the final version.

Heba Abdel-Fatah Ibrahim: data collection, literature review, statistical analysis, manuscript revisions, approval of the final version.

\section{References}

1. Ahmad AR, Murad H, Gardner MR: The Impact of Social Media on Hyped Panic during the COVID-19 Pandemic 'The Iraqi Kurdistan Case. JMIR Ment Health 2020 May 4. doi:10.2196/19556. [Epub ahead of print]

2. Anderson RM, Heesterbeek $H$, Kllinkenberg $D$ \& Hollingsworth TD: How will country-based mitigation measures influence the course of the COVID-19 epidemic? Lancet March 2020; 395:931-934

3. Baek YM, Bae Y, Jang H: Social and parasocial relationships on social network sites and their differential relationships with users' psychological well-being. Cyberpsychol Behav Soc Netw 2013; 16:512-517

4. Becker MW, Alzahabi R, Hopwood CJ: Media multitasking is associated with symptoms of depression and social anxiety. Cyberpsychol Behav Soc Netw 2013; 16:132-135

5. Debanjan D \& Rai M: Social isolation in Covid-19: The impact of loneliness. International Journal of Social Psychiatry. A head of print. 2020. https://doi.org/10.1177/0020764020922269

6. Fisher D, Heymann D\& QA: The novel coronavirus outbreak causing COVID-19. Fisher D, Heymann D. BMC Med 2020; 18:57. doi:10.1186/s12916-020-01533-w

7. Haleem A, Javaid A, Vaishya A: Effects of COVID-19 pandemic in daily life. Current Medicine Research and Practice. Ahead of print. 2020. https://doi.org/10.1016/j.cmrp.2020.03.011

8. Hui DS, I Azhar E, Madani TA, et al.: The continuing 2019-nCoV epidemic threat of novel coronaviruses to global health-the latest 2019 novel corona virus outbreak in Wuhan, China. International Journal of Infectious Diseases 2020; 91:264-266

9. Inter-agency standing committee: Addressing mental health and psychosocial aspects of covid-19 outbreak. IASC Reference Group on Mental Health and Psychosocial Support in Emergency Settings. February. 2020. Available at: https://interagencystandingcommittee.org/system/files/202003/IASC\%20Interim\%20Briefing\%20Note\%20on\%20CO VID-19\%20Outbreak\%20Readiness\%20and\%20Response $\% 20$ Operations\%20-\%20MHPSS_0.pdf. Accessed on: may 52020

10. Jakovljevic M, Bjedov S, Jaksic N, Jakovljevic I: COVID-19 pandemia and public and global mental health from the perspective of global health security. Psychiatr Danub 2020; 32:6-14

11. Jeong H, Yim HW, Song YJ, Ki M, Min JA, Cho J, Chae $J H$ : Mental health status of people isolated due to Middle East Respiratory Syndrome. Epidemiol Health. 2016; 38:e2016048. doi:10.4178/epih.e2016048. eCollection 2016

12. Li S, Wang Y, Xue J, Zhao N, Zhu T: The Impact of COVID-19 Epidemic Declaration on Psychological Consequences: A Study on Active Weibo Users. Int J Environ Res Public Health 2020; 17. pii:E2032. doi:10.3390/ijerph17062032

13. Lovibond SH, Lovibond PF: Manual for the Depression Anxiety Stress Scales. 2. Sydney: Psychology Foundation of Australia, 1995

14. Lucey D, Sparrow A: China Deserves Some Credit for its Handling of the Wuhan Pneumonia. Foreign Policy. Archived from the original. Retrieved April $2^{\text {nd }}, 2020$

15. Maunder R, Hunter J, Vincent L, Bennett J, Mazzulli T: The immediate psychological and occupational impact of the 2003 SARS outbreak in a teaching hospital. Can Med Assoc J 2003; 168:1245-1251

16. Shensa A, Sidani JE, Dew MA, Escobar-Viera CG \& Primack BA: Social Media Use and Depression and Anxiety Symptoms: A Cluster Analysis. American journal of health behavior 2018; 42:116-128. https://doi.org/10.5993/AJHB.42.2.11

17. Shigemura J, Ursano RJ, Morganstein JC, Kurosawa M, Benedek DM: Public responses to the novel 2019 coronavirus $(2019-n C o V)$ : mental health consequences and target populations. Psychiatry Clin Neurosci 2020; 74:281-282. doi: 10.1111/pcn.12988. Epub 2020 Feb 23

18. Tam CWC, Pang EPF, Lam LCW, Chiu HFK: Severe acute respiratory syndrome (SARS) in Hong Kong in 2003: Stress and psychological impact among frontline healthcare workers. Psychol Med 2004; 34:1197-1204

19. Vannucci A, Flannery KM, Ohannessian CM: Social media use and anxiety in emerging adults. $J$ Affect Disord 2017; 207:163-166

20. Wang C, Pan R, Wan X, Tan Y, Xu L, Ho CS \& Ho RC: Immediate Psychological Responses and Associated Factors during the Initial Stage of the 2019 Coronavirus Disease (COVID-19) Epidemic among the General Population in China. International journal of environmental research and public health 2020a; 17:1729. https://doi.org/10.3390/ijerph17051729

21. Wang C, Pan R, Wan X, Tan Y, Xu L, McIntyre RS, Choo $F N$, Tran B, Ho R, Sharma VK, Ho C. A longitudinal study on the mental health of general population during the COVID-19 epidemic in China. Brain Behav Immun. $2020 \mathrm{~b}$ Apr 13. [Epub ahead of print] pii:S0889-1591(20)30511-0. doi:10.1016/j.bbi.2020.04.028

22. World Health Organization a: Coronavirus disease 2019 (COVID-19) Situation Report-110. Available at: https://www.who.int/docs/default-source/coronaviruse/ situation-reports/20200406-sitrep-77-covid19.pdf?sfursn=21d1e632_2 Accessed on: 10 May 2020 
23. World Health Organization b: Clinical management of severe acute respiratory infection when novel coronavirus (nCoV) infection is suspected Interim guidance. Available at: https://www.who.int/publications-detail/ clinical-management-of-severe-acute-respiratoryinfection-when-novel-coronavirus-(ncov)-infection-issuspected. Accessed on: 1/2/2020

24. World Health Organization c: Mental health and psychosocial considerations during the COVID-19 outbreak. Available at:

https://interagencystandingcommittee.org/iascreference-group-mental-health-and-psychosocial- support-emergency-settings/interim-briefing. Accessed on May 32020

25. World Health Organization d: Clinical management of severe acute respiratory infection when novel coronavirus (nCoV) infection is suspected Interim guidance. Retrieved April, $4^{\text {th }}, 2020$ from the following site: http://www.who.int/publications-detail/clinicalmanagement-of-severe-acute-respiratory-infectionwhen-novel-coronavirus-(ncov)-infection-is-suspected

26. Zandifar A, Badrfam R: Iranian mental health during the COVID-19 epidemic. Asian J Psychiatr 2020; 51:101990. doi: 10.1016/j.ajp.2020.101990. [Epub ahead of print]

\section{Correspondence:}

Heba Abdel-Fatah Ibrahim, MD

Maternity and Childhood Nursing Department,

Nursing College, Najran University

Najran, Saudi Arabia

E-mail:heaibrahim@nu.edu.sa 